\title{
An Analysis of the Planning of Public Space Renovation at the Ancient Zhonghuang Village in West Hunan Province
}

\author{
Xingyu Xie
}

\author{
School of Arts, East China University of Technology, Nachang, Jiangxi Province, 344000
}

Keywords: Ancient Villages; Public Space; Remediation and Planning

\begin{abstract}
Public space in ancient villages carries the daily life of villagers. Its reasonable remediation plan can satisfy the villagers' needs for belonging, security and dominance to the event venues, and also meet various requirements for tourists such as sightseeing, communication, leisure and accommodation. Zhonghuang Village in West Hunan Province is known as the "living fossil of ancient villages in Hunan Province". From the aspects of its planning and layout, including natural landscapes, cultural buildings, and renovation measures, this paper expounds the remediation measures and planning patterns of public spaces in ancient villages; meanwhile, it outlines the basic principles, objectives, methods, and measures for the development of ancient villages in west Hunan Province, China.
\end{abstract}

\section{Introduction}

Zhonghuang Village, also known as Zhongwu ancient Miao Village, is located at Aizhai Town, Jishou City, 19 kilometers from Jishou downtown. And it is located in the valley surrounded by MaJian Mountain, Maliang Mountain and Guanyin Mountain, which are more than 800 meters above sea level.

Zhonghuang Village was built in the late Qing Dynasty and has a history of more than 200 years. There are 68 ancient houses, more than 200 rooms and about 13,000 square meters. Most houses are suspended from the top of the mountain and use a bucket-type structure, with five columns and eight melons, and five columns and nine melons. The layout is compact and reasonable and fully functional. It is a rare ancient village at the junction of Jishou, Baojing and Huadu. It is located in the Wuling mountainous area of the Autonomous Prefecture in West Hunan Province and the Yunmai Plateau, and is located at the junction of Hunan, Hubei, Fujian, and Chongqing. It is home to Tujia, Miao, Dong and Yao ethnic groups. There are a lot of ancient villages there, a long time, rich folk customs, rich history and culture, in the process of ethnic migration and home construction continue to form a unique ancient city, ancient village layout and architectural culture characteristics. Zhonghuang Village is close to mountains and rivers, leading to the Zhonghuang Bridge at Zhonghuang Village in Zhonghuang Village. The river under the bridge is clear and there are plants. The reflection is clearly visible. In 2009, the village won the title of "Hunan Provincial Ethnic Village." The inheritance and development of the national characteristics of the ancient villages in Xiangxi will be a major issue for us.

\section{Research on the Public Space at Ancient Zhonghuang Village}

Although Zhonghuang Village is rich in culture, due to the lack of awareness of the protection of the masses, most ancient buildings with historic values have been vandalized, leaving the ancient villages intact. The village has nearly 68 types of buildings, including more than 10 ancient buildings in the Ming and Qing Dynasties, and mainly in the center of the village, such as memorial halls, academies, stage, etc., as well as shops, wells, bridges, ancient tombs, embroidered floor, sun block and well-preserved early European architecture. Among them, the well-preserved wooden Hmong dwelling "seed house" is very representative. In 2013, it was named the first batch of national-level traditional villages, and the second batch of famous tourism villages in Hunan Province.

Zhonghuang Village is planned to be connected by compact households. The Weihe River is 
divided into two parts. The villages along the south of the Weihe River are built around the mountains. The patchwork is obvious. The flat land on the north side of the Weihe River is relatively large, and the village entrance is adjacent to the Weihe River stone arch bridge. There is no apparent axis arrangement in the village. The village is fully functional. Most of the houses are suspended from the top of the mountain. The ancient villagers' homes are in the form of five-pillar and eight-hung wooden houses. The front door is equipped with a directional door, and the house-based and stone-level materials are made of a single piece of bluestone. The well-preserved ancient buildings of the village are connected by six houses with a total length of more than 50 meters. Among them, the gables and the double-cornered Qiaojiao have local architectural features. The wood carved stone carvings, column foundations, window grilles, and colored paintings reflect the rich imagination and thinking ability of the Miao Craftsmen, and their artistic value is relatively high. The village center focuses on buildings such as memorial halls, academies, theatres, shops, wells, bridges, ancient tombs, embroidered houses, and sun houses. The overall environment is decentralized and lacks spatial contact. It is not suitable for modern people's living and commercial development.

Public space generally refers to places where people can freely enter and communicate and communicate. The ancient villages' public space is the place where most people gather in space time and the most activities in ancient villages. It is the material carrier of ancient village public life, and it is also the bearing of various factors such as social, economic, cultural and natural factors in ancient villages. People can enter and exit freely and perform various activities. They can be open spaces, closed or semi-enclosed spaces, ancestral temples, temples, streets, villages, squares, green areas, rivers, piers, and ancient buildings. Under the tree, a small bridge. The layout of the ancient Zhonghuang Village public space is linked to the overall shape of ancient villages, and is limited by the natural landscape structure. It has a lot to do with the concept of "Heaven and Man". The overall layout is rigorous. The Weihe River is surrounded by semicircular arcs and embraces the ancient village. It is backed by Longshan Mountain, left and right Zuofu and Zuoshan Mountain, and the ancient village is located at the top of the mountain. The direction of the axis is facing south from the north, implying that China's feng shui surgery has left Qinglong. The ideal pattern of right-white tiger, former Suzaku, and later basalt[1].

\section{Ancient Zhonghuang Village Public Space Renovation Planning Guidance}

The ancient Zhonghuang Village public space renovation plan is a systematic issue and needs to be considered from different aspects. In terms of function, the public space in Zhonghuang Village is a public place where the villagers live, play, interact with, commercialize, and fitness, and is a major venue for information exchange and cultural heritage of the villagers. Tourism development is one of the important ways for the well-developed Zhonghuang Village. This makes the public space of ancient villages also meet the needs of tourists for tourism, communication, leisure and accommodation. The public space in ancient villages should satisfy the behavior and psychological feelings of all villagers and tourists as much as possible, combine the actual life of the villagers and the needs of industrial development, protect the environment, and economize the use of land to achieve the functional meaning of space.

Formally speaking, the four types of public spaces, including streets, alleys, book buildings, and ancestral halls, determine the variability of public space forms and landscape forms in Zhonghuang Village. Villagers can feel comfortable and happy in these spaces and meet their spiritual and psychological needs. It is in this form that public space in Zhonghuang Village expresses and displays its intrinsic characteristics to people. Therefore, the public space of Zhonghuang Village must realize its harmonious harmony, rhythm, and fulfillment to adjust the psychologists' psychological feelings and achieve the realm of "the combination of things and me." These formal changes have also further promoted the evolution of the public space sequence in Zhonghuang Village.

In addition to the public functions of the Zhonghuang Village public space, it also has a certain significance. The ancient village public space is a venue for villagers to carry out public activities 
and embodies the common values and aesthetic interests of the villagers. When our understanding resonates with the meaning of the public space environment of Zhonghuang Village, we can truly understand the meaning expressed in the space and the ancient village culture. In the planning of public space renovation in Zhonghuang Village, the village's historical and cultural connotations were deeply explored, and through a variety of artistic design methods, space was able to convey the highest level of spiritual joy and beauty on the basis of satisfying the functions and forms, and the meaning expressed by the environment. Resonate deep in people's hearts, and further earthquakes regret people [2].

\section{Ancient Zhonghuang Village Public Space Renovation Planning Design Concept}

In the ancient Zhonghuang Village public space, there is an entrance plaza, a west village entrance, and a stone arch bridge that need to be upgraded. The original site of the Temple of Earth was a village backyard. The present site was rebuilt by donations from foreign residents several years ago. Its image is inconsistent with the culture of the village. Its architectural style is not formal, destroying the overall impression of villagers and tourists on the ancient village. According to the needs of the villagers, the site of the temple was changed to a tourist reception center, which became the most active public place in the village, the main public space core area, and became the space-like space in the space sequence. Restore the effect of the original site of the temple, and build leisure roads and green areas. In order to meet the fitness needs of the elderly and the sports needs of children and adolescents, fitness equipment is added to the entrance plaza, and a children's activity plaza is built at the west village entrance to make these public spaces not only provide services for villagers, but also become places for tourists to play. ${ }^{[3]}$ Stone arch bridge is historically the most popular public space in ancient Zhonghuang Village, but it has not been able to be reasonably used in tourism development. Therefore, in this rectification plan, the stone arch bridge will be upgraded and combined with the Weihe River to carry out recreational activities on the waterfront.

The ancient Zhonghuang Village's public space is also a tourist attraction of the village. Therefore, its landscape effect directly affects the public space's tourist attraction. At present, the public spaces that need to be reconstructed are the node squares, embroidered buildings, and Baozhai buildings in the village. The ancient houses with embroidered houses and watch towers are located in the middle of the village. The direct way of creating landscapes can easily destroy the aesthetic beauty of the villages. Therefore, the ancient houses were trimmed before and after the square, and then the story of throwing the hydrangea and deep embroidery was carefully combined to create another cultural tourist attraction in the ancient village. Next to the Xiulou and Baozhai buildings, the residential buildings can be converted into teahouses, the node plaza can be designed, and kiosks and other small facilities can be added to increase the active atmosphere. The ancient Zhonghuang Village is a Miao Village with a time span. Its tourism development is also based on the village's unique culture. Therefore, the public space in ancient villages should reflect the cultural heritage. In the ancient villages, the temple of the earth is intended to be built with the characteristics of folk traditions as its features. However, the method of building on the original site has weakened the attraction of the culture. In addition, there are flagpoles and Baozhailou in the square with the Temple of Earth. The cultural characteristics of the two are in conflict with the culture embodied in the temple. This destroys the continuity of the context and must be rectified ${ }^{[4]}$.

The most characteristic public space in the ancient Zhonghuang Village becomes an attraction space under the influence of tourism and is connected by the main streets of the village. The entrance plaza is the most iconic public center in ancient Zhonghuang Village. It is a spiritual sustenance for the villagers and a public space for the villagers to feel a sense of belonging and belonging. The existence of the ancient drum tower floor makes villagers aware of their own kind of home. The relationship between mentality. The stone arch bridge was once a public center of ancient villages, a commercial and transportation center, and can be built as another public center of an ancient village. Therefore, the public space sequence plan for the ancient Zhonghuang Village is divided into two parts, namely the waterfront sequence and the chessboard sequence. The 
waterfront square centered on the stone arch bridge and the farmland style street with strips as the main surface public space are connected by the waterfront axis generated by the transit road to form a waterfront public space sequence with excellent landscape. The Zhonghuang Village chessboard lanes link all public spaces together, with entrances and plazas, embroidered buildings and reception centers, tea houses, and Baozhai buildings forming three communal public spaces respectively, constituting the most important spatial sequence of the chessboard public in ancient Zhonghuang Village.

\section{Ancient Zhonghuang Village Public Space Renovation Implementation and Management}

The management of the implementation of the public space remediation planning in ancient villages is a complex and systematic social project that can be divided into the following points.

Regarding Zhonghuang Village, Sound Policies and Regulations should be Established, and Laws and Policies do not exist in Isolation. The relationship with the existing series of laws and regulations and technical standards should be clearly defined so as to be more realistic and operational.

Improve the Management Institutions, Learn from the Experience of Foreign Planning and Management and Consider China's National Conditions. With the government's administrative management organization as the leading factor, the separate management mechanism for approval, planning management and planning supervision of the public space remediation planning in Zhonghuang Village was established. The special department will coordinate the interests of various departments, and finally form a comprehensive policy, and then implement it. Through this type of network structure that is separately managed, a hierarchically structured, definite and efficient planning and management organization system can be formed.

Strengthen the Publicity of Education among Villagers. Most of the villagers in Zhonghuang Village lacked the concept of public space. It is not clear that this is closely related to the society, economy, ecology, and their lives of Zhonghuang Village. Villagers can gain relevant knowledge about the public space of ancient villages and make them realize that public space renovation planning not only improves their living environment and protects the ecological environment, but more importantly relates to their own economic interests. ${ }^{[5]}$

Pay Attention to the Maintenance of Public Space. If something unfavorable happens, such as the villagers demolition and construction, they are all caused by insufficient management. The establishment of a non-governmental conservation organization and repair team will manage and maintain the public space in ancient villages.

To implement the phased Construction, the Implementation and Management of the Public Space Remediation Planning in Zhonghuang Village needs to be Implemented in Phases, and Different Management Implementation Methods are Formulated at Different Times to Ensure the Normal operation of the Planning and Rectification of Public Spaces in Ancient Villages [3].

In terms of Maintenance and Renovation, we Adhere to the Principles of Scientific Repairs and Rescue and Protect cultural Relics and Historic Sites in Ancient Villages. In the course of maintenance and renovation of ancient buildings, the cultural relics protection units should strictly follow the protection principle of "does not change the original state" to carry out repairs. The traditional buildings and historical streets are strictly required to use the original structure, raw materials, and original technology. The repairs of private houses are all incorporated into the government's unified regulations and the government provides certain assistance and financial subsidies. The design and construction unit strictly checks, takes the necessary ancient building knowledge training and technical guidance for construction personnel, and adopts different methods for different types of ancient buildings.

In Terms of Village Construction, with the Improvement of the Conditions of Use of Traditional Buildings, the facade of the Building should be Modified so that it is Consistent with the Traditional Village Space and the Content can be Modernized to Meet the Needs of Modern Life. There are still a certain number of buildings in the ancient villages to adapt to the 
stability and development of the community. The total amount of new buildings should be strictly controlled so as to maintain the shape and spatial texture of ancient villages. The new buildings must be strictly coordinated with traditional styles in their style. In the building decoration materials, methods, building mass, height, color, proportion consistent with the ancient building, the structure of the use of modern structural functions ${ }^{[6]}$.

\section{Conclusion}

Ancient villages have a variety of public spaces and all have their own characteristics. This paper proposes that public Zhonghuang Village's planning and guidance of public space must follow the principles of system planning, continuity in space, people-centeredness, adaptation to local conditions, public participation, harmony and sustainability, and strive to improve the function, form, and significance of the public space after rectification.

Ancient villages in Hunan Province have a long history and are historical and cultural towns and famous villages with conservation values. To fully reflect the spatial characteristics of ancient villages in western Hunan, this requires that a unified model cannot be implemented in the construction of villages, and the relationship between protection and inheritance, development and inheritance must be handled hierarchically. The first is the protection and inheritance of historical and cultural villages. In the process of rectification, it is mainly inherited from traditional cultures, and preserves the traditional space and pattern of history. The second is that for the old villages, they advocate the importance of inheritance and development. The main emphasis is on coordinated development. Without prejudice to the historical space, it focuses on reflecting the continuation of the history of the village. Third, the development of new villages in the ancient villages must embody the quest for impersonation in the local characteristics of ethnic groups, and oppose blindly retro and antique styles, focusing on the repeated application and manifestation of ethnic village space and architectural symbols.

Economic development, speeding up the reconstruction of ancient villages, and constructive destruction of ancient villages; non-indigenous architectural decoration techniques and modern new materials are constantly emerging. The ancient and simple ancient villages will become completely unrecognizable. Some villages put too much emphasis on the protection of ancient buildings in Western Hunan, neglecting the protection of the entire ancient villages; how the quality of life of the villagers has improved and how the community has protected the stability. These issues have brought many new issues for the protection of ancient villages' historical and cultural heritage. In order to maintain the authenticity and integrity of ancient villages, protect the landscape environment of ancient villages, promote the healthier development of ancient villages, and promote their protection and management to a virtuous cycle, follow-up management work should be carried out promptly after the preparation of ancient village conservation plans.

Most of the ancient buildings in Huangzhong Village were made of wood materials. They were in disrepair for a long time. Some of the old building components were damaged, and some of the buildings were brick and concrete structures. Although the standard is Diaojiaolou, the colors are different and the spatial order is chaotic, which seriously affects the cultural characteristics of ancient villages. The existing spatial planning is the result of the natural development of its history. The spatial dimensions are small and it is not suitable for group activities and does not meet ergonomics. For the reinforcement design of wooden ancient buildings, the structure can be changed without changing the original appearance, and the old ones can be replaced with new ones, and tung oil can be used to prevent rust and insect repellent paint. In the recent brick-concrete structure, it is necessary to carry out an appearance transformation to restore the surface of the wood. Space planning minimizes the road system to suit the needs of community activities.

The transformation of residential buildings into commercial spaces will affect the appearance of ancient settlements. The re-planning of public spaces will affect the original arrangement of ancient villages. Over-development and commercialization will result in the loss of the characteristics of Zhonghuang Village. The commercial space of the residential buildings was relocated to the same street as far as possible. The standard and the form were the same. The side of the building was 
considered to add local architectural components. The entrance and exit of the residential area was set up with wooden building archways, which increased the similarity of the appearance of the buildings. The replanning of public spaces should try to arrange the original open space and use the walking roads and green design to connect the landscape nodes.

Finally, the management of the implementation of the public space remediation planning at the ancient Zhonghuang Village is a guarantee for the normal operation of the rectification work. It should establish sound policies and regulations, improve a reasonable management organization, pay attention to the maintenance of public space, establish special funds, and implement the construction in phases according to actual needs. .

\section{References}

[1] Duan Jin, Gong Yi, et al. Space Research 1: Analysis of the World Cultural Heritage of Xidi Ancient Villages [M]. Nanjing: Southeast University Press, 2006: 37.

[2] Zhou Luanshu. No.1 Village in the History --A Survey of Liukun's History and Culture [M]. Nanchang: Jiangxi People's Publishing House, 1997. 26 284.

[3] Yang Di. Study on Public Space Renovation Planning of Xishan Ancient Village in Taihu Lake [D]. Suzhou University of Science and Technology, 2010.

[4] Li Huawei. Changes of Public Space in Rural Areas and Construction of People's Life Order: A Case Study of the Interaction between Clans, Temple Fair, and Rural Christianity in Lixi, Western Henan Province [J]. Folklore Studies, 2008(4): 72-101.

[5] Chen Jinquan et al. The Sociological Significance and Planning Design of Rural Public Space [J]. Journal of Jiangxi University of Science and Technology, 2007, 28(2): 74-77.

[6] Lin Xuechun. A Review of the Study of Village Governance Models since the Self-government of Contemporary Chinese Villagers [J]. Agricultural Economics Guide, 2006(5): 74-79.

Fund project: the department of jiangxi province in 2016 college humanities and social science research project of "research - jiangxi ancient village space structure elements in AnYi village " (project number: YS1503).

Introduction to the Author: Xingyu Xie (1982-), male, born in Changchun, Jilin Province, currently teaches at the Huanyi University of Technology Art Director. Research direction: Environmental Design, Habitat Engineering. 